\title{
Prevalence of precancerous lesions among positive HIV women in the hospital complex and University of Yaounde (Cameroun)
}

\author{
Djuendje DVS ${ }^{1}$ and Kamdje $\mathrm{AHN}^{2 *}$ \\ ${ }^{1}$ Evangelical University of Mbouo-Bandjoun, Cameroon \\ ${ }^{2}$ Department of Biomedical Sciences, Faculty of Sciences, University of Ngaoundere, Ngaoundere, Cameroun
}

\begin{abstract}
In the year 2000, a wide campaign of screening and treatment of the dysplastic lesions of the cervix was initiated in Cameroun. The precancerous lesions of the cervix are the most important demonstration of gynecological infection by the AIDS. As these lesions remain little documented in Cameroun, we carried out a study which the goal was to determine the prevalence of the precancerous lesions among positive AIDS women.

It is about a descriptive study with a retrospective collection of data carried out between 2010 and 2016 among 253 positive AIDS women having carried out a consultation in the Hospital complex and University of Yaounde aged from 18 to 80 years. The analysis of the data was essentially carried on: the age, clinical Factors data of risk of the precancerous lesions, anatomo-pathological search of precancerous lesion. AIDS status and/or the catch the antiretroviral one. The Software SPSS was used for the analysis of data. The test of $\mathrm{Chi} 2$ for the comparison of the variables. A variable was considered significant if $\mathrm{P}<0.05$.

53 women presented precancerous lesions i.e. 20,94\%. The lesions were in $92 \%$ of the squamous lesions with intra epithelial of low rank and in $8 \%$ of the squamous lesions with intra epithelial of high rank. 22 women (38\%) were aged between 36 and 45 years; 22 women (40\%) were housewives; 18 women (31\%) were single people; 36 women (67\%) were multipares; 45 women (85\%) did not smoke; 33 women (62\%) had a peak of CD4 located between $500-1000 / \mathrm{mm}^{3} ; 14$ women $(26 \%)$ did not have opportunist diseases 10 women (19\%) had the zona, 8 women (15\%) of tuberculosis and 9 women (17\%) suffered from HTA.

Because of the high potential risk of precancerous lesions in our population of study, we recommend a regular clinical follow-up of the patients presenting high factors of risk, and a widened access to antiretroviral.
\end{abstract}

\section{Introduction}

The Acquire Immuno Deficiency Syndrome (AIDS) is responsible for the greatest viral pandemic. This is a virus which acts on the immune system by weakening it and thus allowing the development of opportunist diseases which lead to the death of the person. In the world, we counted 33,2 million people living with AIDS. In subSaharan Africa 25,8 million people are living with AIDS. The women represent more half of the total number of the people living with AIDS in sub-Saharan Africa [1]. More than 5\% of this 22 million (population of Cameroun) are carrying this virus in Cameroun and the women account for $61 \%$ of the carriers of this virus [2]. This virus acts on the immune system which will be a favorable ground for other pathologies quite as dangerous as cancers. The most representative cancer for the woman is the cancer of the cervix.

The cancer of the cervix is at the origin of 3387 new cases and of 1000 deaths per annum corresponding to an average incidence of 8 per 100000 person-years in 2000. It is located at the $2^{\text {nd }}$ rank of female cancers in term of incidence and there thus remains a priority to public health [3]. In Cameroun one estimates that approximately 1400 to 1700 new cases of cancer of the cervix per annum and approximately 700 of them die each year [4]. The cancer of the cervix is preceded during 10 to 15 years by precancerous lesions. Those are detectable by the smear and their treatment makes it possible to avoid or reduce the risk of evolution towards an invasive cancer. The screening of the cancer of the cervix in France is individual but there are recommendations for clinical practice where it is advised to carry out a smear every 3 years after 2 normal annual smears for women from 25 to 65 years.

A precancerous state of the cervix is characterized by changes undergone by the cells of the collar which make them more likely to evolve in a cancer. This state is not yet a cancer, but it is strongly likely to be transformed into cancer of the cervix in 10 years or more if it is not treated in time. One finds a cervical dysplasia at 1 to $5 \%$ of the women in the general population. They concern primarily the young, old women from 25 to 35 years. It is estimated that each year, appear approximately 69000 new cases of dysplasia of low rank and 15000 cases of dysplasia of high rank in France. The papillomavirus (Human Papillomavirus: HPV) are known and are very many. They are responsible for a multitude of lesions found on the skin or the mucous membranes. By infecting the cells of the cervix, they lead to lesions which at term can evolve to a cancer. The Co-infection by

Correspondence to: Armel Herve NWABO KAMDJE, Department of Biomedical Sciences, University of Ngaoundere, Ngaoundere - Cameroon; Tel: +23777463063/+23790190421; E-mail:kamdjewa@yahoo.fr/ah.nwabo@univ-ndere.cm

Key words: precancerous lesions, aids, prevalence

Received: January 23, 2017; Accepted: February 13, 2017; Published: February 16,2017 
viruses AIDS and HPV is at the origin of a growing number of cancers for seropositive people. A new study on nearly a half-million patients shows it with force [5]. The objective of our study was to determine the prevalence of precancerous lesions in patients infected by AIDS.

\section{Materials and methods}

It was about a descriptive study with retrospective collection of data, realized between 2010 and 2016 among women aged from 18 to 80 years having carried out a consultation in the Hospital complex and University of Yaounde in the services of the laboratory of Anatomocyto-pathology and external consultation were included in our study all the files of patients containing of factors of risk of the precancerous lesions, anatomo-pathological search of precancerous lesions, AIDS status and/or the take in of antiretroviral. The data were gathered and analyzed in the software Microsoft Office Excel 2007 and SPSS 16.0. The test of Chi2 for the comparison of the variables. A variable was regarded as significant if $\mathrm{P}<0.05$.

\section{Results}

On 253 AIDS positive indexed women, 53 (that is to say 20,94\%) entered in our criteria, including 47 of the LSIL 5 HSIL and 1 ASCUS. Table I summarizes the socio demographic profile.

The general characteristics of the 53 positive AIDS women having precancerous lesions are set out in table I. The most represented age group is that ranging between 36 to 45 years (38\%) whatever the type of lesions the age bracket is more represented same as that observed in our population study. The dominant profession is those of the housewives (41\%), the matrimonial status that of the single people $(32 \%)$ approximately $67 \%$ of the population study is composed of multipare

Table 1. General characteristics of the population study.

\begin{tabular}{|c|c|c|}
\hline $\begin{array}{l}\text { Characteristics } \\
\mathrm{N}=\mathbf{5 3}\end{array}$ & Number & Percentage (\%) \\
\hline \multicolumn{3}{|l|}{ Age } \\
\hline $21-25$ & 1 & 2 \\
\hline $26-35$ & 6 & 14 \\
\hline $36-45$ & 22 & 38 \\
\hline $46-55$ & 13 & 23 \\
\hline $56-65$ & 9 & 19 \\
\hline $66-75$ & 2 & 4 \\
\hline \multicolumn{3}{|l|}{ Profession } \\
\hline civils servant & 7 & 13 \\
\hline teachers & 7 & 13 \\
\hline business & 12 & 23 \\
\hline dressmakers & 4 & 8 \\
\hline students & 1 & 2 \\
\hline housewives & 22 & 41 \\
\hline \multicolumn{3}{|c|}{ Marital status } \\
\hline Married & 14 & 26 \\
\hline Single person & 17 & 32 \\
\hline Divorced & 4 & 8 \\
\hline Widow & 14 & 26 \\
\hline Free union & 4 & 8 \\
\hline \multicolumn{3}{|l|}{ Parity } \\
\hline Nullipare & 6 & 12 \\
\hline primipare & 11 & 21 \\
\hline Multipare & 36 & 67 \\
\hline \multicolumn{3}{|l|}{ Smoking } \\
\hline YES & 8 & 15 \\
\hline NOT & 45 & 85 \\
\hline
\end{tabular}

Table 2. Pattern of the population study according to the type of precancerous lesion and the factors of risks.

\begin{tabular}{|l|c|c|c|c|}
\hline & \multicolumn{4}{|c|}{ Types of lesions } \\
\hline Opportunist diseases & LSIL (\%) & HSIL (\%) & ASCUS (\%) & TOTAL (\%) \\
\hline HTA & 15 & 2 & 0 & 17 \\
\hline shingle & 11,3 & 5,7 & 2 & 19 \\
\hline Tuberculosis & 13 & 2 & 0 & 15 \\
\hline Gastritis & 7 & 0 & 0 & 7 \\
\hline Anemia & 8 & 0 & 0 & 8 \\
\hline Candidioses & 8 & 0 & 0 & 8 \\
\hline No diseases & 24 & 2 & 0 & 26 \\
\hline Rate of CD4 & & & & \\
\hline$<500 / \mathrm{mm}^{3}$ & 30 & 2 & 0 & 32 \\
\hline $500-1000 / \mathrm{mm}^{3}$ & 52,5 & 5,5 & 2 & 62 \\
\hline $1000-1500 / \mathrm{mm}^{3}$ & 4 & 2 & 0 & 6 \\
\hline
\end{tabular}

and in $85 \%$ of the cases are nonsmokers. In spite of the various types of lesions the dominant profession is same as that observed in our population study. When it comes to the LSIL of single people and multipares are more represented; the widows and the primipare when it is HSIL whatever the type of lesions the patients are nonsmokers.

$26 \%$ of the women of our population study do not expressed opportunist diseases. On the other hand, those who expressed had the shingle in $19 \%$ of the cases. According to the precancerous lesions the HTA is more found among women having intra epithelial lesion of low grade and shingle among women having intra epithelial lesion of high rank. Even as the rate of cd4 dominating is that ranging between 500$1000 / \mathrm{mm}^{3}$ no matter the type of lesion. The prevalence of precancerous lesions in our population was $20,94 \%$ It is higher than that found by Tebeu et al. [6] in the Cameroun general population, which is $3.9 \%$, which is higher than that found in the center region which is $5.01 \%$. This tallies with the assertions according to which the AIDS constitutes a factor of risk of precancerous lesions. Juluis Atashili et al. in 2008 [7] in 3 hospitals of Cameroun in patients who were at their first year of treatment, had found a prevalence of $43,5 \%$ of precancerous lesions. This prevalence higher than ours could be explained by the fact that the median rate of CD4 in this population was low compared to that found in our population ( $179 \mathrm{vs} 581,43 / \mathrm{mm} 3$ ). The most encounter lesions are those of LSIL (89\%). These results are almost similar to that of Antoine J who has a preponderance of LSIL [8] and contrary with the results found by Kabeyene Okono and al. into 2015 who has a preponderance of inflammatory lesions [9] and opposite with that found by Motgomo et al. [10] which showed a prevalence of the lesions of high rank among women infected by AIDS in Douala. The most touched age group is $36-45$ years the average age being of $46.35+/-10,63$ years be it $38 \%$. The most represented age group can be explained by the fact that it is the age at which women sexually active. These results are close to that found by CLAIRE CRITON in Central African Republic (Bangui) for which the most touched age group is that of 31-45 years [11].

$40 \%$ of our patients were housewives this could be explained by the great frequency of this profession in the Cameroun female population. The study show us that they are the unmarried women and multipares which are mostly exposed which corroborates with the results found by ANTOINE J in Ivory Coast showing that the parity and the fact of live alone is associated to a high risk to present precancerous lesions [8]. $85 \%$ of the women are the nonsmokers. Knowing that smoking is a factor of risk of precancerous lesion, was not the case in our study. Generally, smoking is exceptional among women in our country [12].

The more frequent diseases are the shingles (19\%), hypertension 
(17\%) tuberculosis (15\%), And that certain patients do not have opportunist diseases $(26 \%)$ we cannot establish a relation between opportunist diseases and precancerous lesions All our patients were under treatment of ARV and had a rate of CD4 ranging between 500 and $1000 / \mathrm{mm} 3(62 \%)$ This value $(62 \%)$ is a little higher than those found in the majority of studies [13-15]. This could be justified by the fact that, our positive AIDS patients for the majority were already followed up in CHUY and moreover the Cameroun government ensures free treatment of all the seropositive patients with a rate of CD4 lower than 500 [16-20].

\section{Conclusion}

The results of our study revealed a prevalence of precancerous lesions among positive AIDS women of $20.94 \%$ higher than that found former studies. This shows us a high risk of precancerous lesions among these women. One of the interests of this study is that it describes the factors of risk to have a lesion neither the youth nor the fact smoking are factors of risks (whereas it is the case among seronegative women) the rate of CD4 is not either a factor of risk. We recommend a regular clinical follow-up of the patients at risk and the best take care of positive AIDS women.

\section{Authorship contribution}

All authors contributed to the design, preparation, editing, and final review of the manuscript.

\section{Acknowledgments}

Authors thank the collaborators of their respective institutions for the comments on the manuscript.

\section{References}

1. WHO (2010) Cervical cancer in the African Region of WHO: current situation and prospects. Regional Committee for Africa.

2. Pierre A (2013) Cancers in developing countries. Tropical medicine. P 01.

3. Yeni P (2010) Management of people infected with HIV. Recommendation of the expert group. The French documentation. Paris 417 pages. ISBN 978-2-11-008038-7.

4. Cervical Cancer Action (2012) Progress towards cervical cancer prevention: A review of the CCA. P 6.
5. GLOBOCAN (2008) Estimated cancer incidence, mortality, prevalence and disability adjusted life years (DAYLYS). Worldwide in 2008. IARC

6. ACCP (2011) Prevention of cervical cancer. Help memory.

7. Tebeu P M, Sandjong I, Nkele N, Foukoua S, Achu P, et al. (2005) Precancerous lesions of the cervix in rural areas: cross-sectional study. Medicine d'Afrique noire 52: 28-30

8. ECLAIRAGES (2011) Health information bulletin / Cameroon 3: 1.

9. ACCP (2006) Planning and implementation of programs for the prevention and control of cervical cancer. Handbook for organizers.

10. High Authority of Health (HAS) (2013) Screening and prevention of cervical cancer Update of the practice of the periodic health examination. P 4

11. Mesonego J (2006) Prevention of cervical cancer: challenges and prospects for vaccination against papillomavirus. Obstetric Gynecology \& Fertility 34: 189-201.

12. Stoler MH, Schiffman M (2001) Interobserver reproductibility of cervical cytology interpretation realistic estimates from ASCUS-LSIL. Titration study Jama 285: 15001505. [Crossref]

13. Farahnaz K, Anisodowleh N, Taravat F, Mansour R, Ahmad K, et al. (2013) Cervical visual inspection with acetic acid as an alternative screening test for cervical cancer detection. International Journal of Collaborative Research on Internal Medicine \& Public Health 5: 1.

14. World Health Organization (2007) Fight against cervical cancer. Essential Guide Practices.

15. Suriya P, Aiyavu C, Gobinath S (2016) Screening and prevention of HPV infected cervical cancer. IJESC 6: 5 .

16. Nkegoum B, Belley Priso E, Mbakop A, Gwet bell E (2001) Precancerous lesions of the cervix in Cameroonian women. Cytological and epidemiological aspects of 946 cases. Gynécol OhstétFellil. 29. [Crossref]

17. Doh A S, Kouam L (1999) The management of preinvasive cervical lesion using cryotherapy in Yaounde, Cameroon. J Obstet Gynecol 19: 6.

18. Mpiga E, Mahine I, Koumakpayi I, Engohan-Aloghe C, Chansi Ankély J, et al. (2015). Interest of visual inspection with acetic acid and lugol solute with colposcope in the detection of cervical lesions in Gabon. Pan African Medical Journal.

19. Fofana M (2003) Early detection of precancerous lesions of the cervix in Bourkina Faso: A comparative study of visual inspection after application of acetic acid (VIA) and lugol (VILI). Thesis presented to obtain the special study certificate (SSC) of obstetric gynecology. University of Ouagadougou, Burkina Faso.

20. Duport N (2008) Epidemiological data on cervical cancer. States of knowledge. INVS

Copyright: (C2017 Djuendje DVS. This is an open-access article distributed under the terms of the Creative Commons Attribution License, which permits unrestricted use, distribution, and reproduction in any medium, provided the original author and source are credited. 